\title{
Boolean network modeling of $\beta$-cell apoptosis and insulin resistance in type 2 diabetes mellitus
}

\author{
Pritha Dutta ${ }^{1}$, Lichun $\mathrm{Ma}^{2}$, Yusuf Ali $^{3}$, Peter M.A. Sloot ${ }^{4}$ and Jie Zheng ${ }^{5^{*}}$ \\ From The 17th Asia Pacific Bioinformatics Conference (APBC 2019) \\ Wuhan, China. 14-16 January 2019
}

\begin{abstract}
Background: Major alteration in lifestyle of human population has promoted Type 2 diabetes mellitus (T2DM) to the level of an epidemic. This metabolic disorder is characterized by insulin resistance and pancreatic $\beta$-cell dysfunction and apoptosis, triggered by endoplasmic reticulum (ER) stress, oxidative stress and cytokines. Computational modeling is necessary to consolidate information from various sources in order to obtain a comprehensive understanding of the pathogenesis of T2DM and to investigate possible interventions by performing in silico simulations.

Results: In this paper, we propose a Boolean network model integrating the insulin resistance pathway with pancreatic $\beta$-cell apoptosis pathway which are responsible for T2DM. The model has five input signals, i.e. ER stress, oxidative stress, tumor necrosis factor $\alpha$ (TNF $\alpha$ ), Fas ligand (FasL), and interleukin-6 (IL-6). We performed dynamical simulations using random order asynchronous update and with different combinations of the input signals. From the results, we observed that the proposed model made predictions that closely resemble the expression levels of genes in T2DM as reported in the literature.
\end{abstract}

Conclusion: The proposed model can make predictions about expression levels of genes in T2DM that are in concordance with literature. Although experimental validation of the model is beyond the scope of this study, the model can be useful for understanding the aetiology of T2DM and discovery of therapeutic intervention for this prevalent complex disease. The files of our model and results are available at https://github.com/JieZhengShanghaiTech/boolean-t2dm.

Keywords: Boolean model, Type 2 diabetes mellitus, Insulin resistance, $\beta$-cell apoptosis

\section{Background}

Type 2 diabetes mellitus (T2DM) is characterized by insulin resistance at its onset. Persistence of insulin resistance leads to pancreatic $\beta$-cell dysfunction and in extreme cases to $\beta$-cell apoptosis [1-3]. Insulin resistance increases the load on $\beta$-cells to produce more insulin in order to maintain blood glucose at normal levels. This homeostasis is maintained as long as $\beta$-cells can meet the increased insulin demand. However, persistence of

\footnotetext{
*Correspondence: zhengjie@shanghaitech.edu.cn

${ }^{5}$ School of Information Science and Technology, ShanghaiTech University, Shanghai, China

Full list of author information is available at the end of the article
}

excessive nutrients could lead to hyperglycemia, elevated free fatty acids (FFA), and inflammation, which severely impair $\beta$-cell functions, leading to insulin resistance and $\beta$-cell apoptosis.

The ER in the $\beta$-cells is responsible for the production and secretion of insulin. The increased demand for insulin synthesis in the presence of high glucose and FFA levels triggers the accumulation of misfolded proteins in the ER, causing ER stress and the consequent activation of the unfolded protein response (UPR). UPR initially attempts to mitigate ER stress by degrading misfolded proteins and preventing their further accumulation. However, when ER stress is not mitigated, UPR activates the apoptosis signals [4-6]. $78 \mathrm{kDa}$ glucose regulated protein (GRP78) serves 
as a sensor of protein misfolding [7]. Under non-stressed conditions, GRP78 binds to three UPR initiator proteins, i.e. inositol requiring 1 (IRE1), PKR-like ER kinase (PERK), and activating transcription factor 6 (ATF6), and maintains them in the inactive state [8]. Under stressed conditions, GRP78 dissociates from these three proteins, causing their activation and initiation of UPR.

When ER stress can be resolved, the UPR assists $\beta$ cells in their survival. However, when ER stress cannot be resolved the UPR activates the pro-apoptotic signals [9]. Hyperglycemia causes oxidative stress through the generation of reactive oxygen species (ROS) [10]. In the absence of an appropriate antioxidant response, the system experiences redox imbalance, leading to the activation of oxidative stress-sensitive signaling pathways. Cytokines, including FasL, TNF $\alpha$, and IL-6, play important roles in the induction of $\beta$-cell apoptosis [11-15] as well as insulin resistance $[16,17]$. Caspases serve as the final mediators of apoptosis. The upstream apoptosis initiator caspases 8 and 9 are activated on receiving death signal from the death-inducing signaling complex (DISC) and apoptosome respectively, which in turn activate the downstream apoptosis effector caspases 3, 6 and 7, which ultimately execute apoptosis [18].

Computational modeling is necessary to consolidate information from various sources, such as listed above, in order to obtain a comprehensive understanding of the pathogenesis of T2DM and investigate possible interventions by performing in silico simulations. A few dynamic models of insulin resistance in T2DM have been proposed recently. For instance, Brannmark et al. [19] proposed an ordinary differential equation (ODE) model of insulin signaling in T2DM. Rajan et al. proposed an ODE model to study the contribution of Forkhead box protein O1 (FOXO1) to insulin resistance in T2DM [20]. Another paper [21] presented an ODE model to simulate the development of insulin resistance by hyperglycemia, FFA, ROS, and inhibition of glucose transporter type 1 (GLUT-1) and glucose transporter type 4 (GLUT-4). However, there exists no model of $\beta$-cell apoptosis occurring in the T2DM condition. Also, there is no existing work that attempts to integrate the insulin resistance and $\beta$-cell apoptosis pathways in order to obtain a comprehensive understanding of the molecular mechanisms underlying T2DM. To discover potential therapeutic interventions for T2DM, it is essential to have a more comprehensive model for the mechanisms causing T2DM pathogenesis.

Therefore, we propose a Boolean network model integrating the insulin resistance pathway and $\beta$-cell apoptosis pathway for the purpose of obtaining deeper insights into the mechanisms of development and progression of T2DM. The aforementioned existing models are ODE models, whereas we constructed a Boolean network model. The reason behind this selection is that
ODE models require detailed kinetic knowledge and time-series data for accurate parameter estimation. However, the size of our proposed network is relatively big (consisting of 72 nodes) and hence obtaining time-series expression data for all the genes would be expensive as well as time-consuming. Also, estimating the parameters of the ODE model with the time-series expression data of only a small subset of genes would result in erroneous parameter values. Furthermore, in a Boolean network

Table 1 The gene interactions incorporated into the model with reference to the existing literature

\begin{tabular}{|c|c|}
\hline Gene interations & Reference \\
\hline IRE1 $\uparrow \rightarrow \mathrm{XBP} 1 \uparrow \rightarrow \beta$-cell dysfunction & {$[26]$} \\
\hline $\begin{array}{l}(\text { IRE1 + TRAF2 + ASK1) } \uparrow \rightarrow J N K \uparrow \rightarrow B C L 2 \\
\text { (anti-apoptotic gene) } \downarrow\end{array}$ & [28-30] \\
\hline BCL2 $\downarrow \rightarrow(B A X+B A K)$ (pro-apoptotic) $\uparrow$ & {$[50,51]$} \\
\hline $\begin{array}{l}\text { PERK } \uparrow \rightarrow \text { EIF2S1 } \downarrow \rightarrow \text { ATF } 4 \uparrow \rightarrow \text { CHOP (pro- } \\
\text { apoptotic) } \uparrow\end{array}$ & {$[27]$} \\
\hline $\begin{array}{l}\text { ATF6 } \uparrow \rightarrow \text { CHOP (pro-apoptotic) } \uparrow \rightarrow \text { BCL2 } \\
\text { (anti-apoptotic gene) } \downarrow\end{array}$ & {$[51,52]$} \\
\hline Oxidative stress $\uparrow \rightarrow$ ASK $1 \uparrow, J N K \uparrow$, p38 $\uparrow$ & [31-33] \\
\hline p38 $\uparrow \rightarrow$ CHOP (pro-apoptotic) $\uparrow$ & {$[34]$} \\
\hline $\begin{array}{l}\text { Fas } L \uparrow \rightarrow(\text { Fas } R+\text { FADD }+ \text { pro-caspase- } 8) \uparrow \\
\rightarrow \text { caspase- } 8 \uparrow \rightarrow \text { caspase- } 3 \uparrow \rightarrow \text { apoptosis }\end{array}$ & [53] \\
\hline $\begin{array}{l}\text { TNF } \alpha \uparrow \rightarrow(\text { TNFR } 1+\text { TRADD }) \uparrow \rightarrow \text { RIPK } 1 \uparrow, \\
\text { FADD } \uparrow, \text { TRAF2 } \uparrow\end{array}$ & {$[54]$} \\
\hline FADD $\uparrow \rightarrow$ caspase- $8 \uparrow$ & {$[54]$} \\
\hline RIPK $1 \uparrow \rightarrow$ RAIDD $\uparrow \rightarrow$ caspase- $8 \uparrow$ & {$[54]$} \\
\hline $\begin{array}{l}\mathrm{TNF} \alpha \uparrow \rightarrow \text { TNFR2 TNF } \alpha \uparrow \rightarrow \text { TRAF2 } \uparrow \rightarrow \\
\ldots \rightarrow \mathrm{JNK} \uparrow, \mathrm{NF}-\mathrm{kB} \uparrow\end{array}$ & {$[55-57]$} \\
\hline $\begin{array}{l}(\text { BAX }+ \text { BAK) } \quad \text { (pro-apoptotic) } \uparrow \rightarrow \\
\text { Cytochrome C } \uparrow \rightarrow \text { (APAF1 + caspase-9) } \uparrow \\
\rightarrow \text { caspase-3 } \uparrow\end{array}$ & {$[6,58]$} \\
\hline $\begin{array}{l}\text { XIAP } \uparrow \rightarrow \text { caspase- } 3 \downarrow \text {, caspase- } 7 \downarrow \text {, caspase- } \\
9 \downarrow\end{array}$ & {$[35,36]$} \\
\hline $\mathrm{DIABLO} \uparrow, \mathrm{HtrA} 2 \uparrow \rightarrow \mathrm{XIAP} \downarrow$ & {$[37]$} \\
\hline $\begin{array}{l}\mathrm{INSR} \uparrow \rightarrow \operatorname{IRS} \uparrow \rightarrow \mathrm{PI} 3 \mathrm{KK} \uparrow \rightarrow \ldots \rightarrow \mathrm{AKT} \uparrow \rightarrow \\
\mathrm{FOXO} 1 \downarrow, \mathrm{GSK} 3 \beta \downarrow, \mathrm{GLUT4} \uparrow\end{array}$ & [59-61] \\
\hline GSK3 $\beta \uparrow \rightarrow$ GS $\downarrow \rightarrow$ glycogen synthesis $\downarrow$ & {$[42,43]$} \\
\hline $\begin{array}{l}\text { FOXO1 } \uparrow \rightarrow \text { PEPCK } \uparrow, \text { G6PC } \uparrow \rightarrow \text { glucose } \\
\text { synthesis } \uparrow\end{array}$ & {$[47,47-49]$} \\
\hline$(\mathrm{mTORC} 1+\mathrm{S} 6 \mathrm{~K}) \uparrow \rightarrow \mathrm{IRS} \downarrow$ & [44-46] \\
\hline $\mathrm{IKK} \beta \uparrow \rightarrow \mathrm{TSC} 1 / 2 \downarrow \rightarrow \mathrm{mTORC} 1 \uparrow$ & {$[62]$} \\
\hline $\begin{array}{l}\text { ER stress } \uparrow \rightarrow \ldots \rightarrow \operatorname{IRE} 1 \uparrow \rightarrow \ldots \rightarrow \mathrm{JNK} \uparrow \rightarrow \\
\text { IRS } \downarrow\end{array}$ & {$[38,39,63]$} \\
\hline $\begin{array}{l}\text { ER stress } \uparrow \rightarrow \ldots \rightarrow \text { IRE1 } \uparrow \rightarrow \mathrm{XBP} 1 \uparrow \rightarrow \\
\text { FOXO1 } \downarrow\end{array}$ & [64] \\
\hline $\mathrm{PERK} \uparrow \rightarrow \mathrm{FOXO} 1 \uparrow$ & {$[65]$} \\
\hline $\begin{array}{l}\text { ER stress } \uparrow \rightarrow \ldots \rightarrow \text { ATF4 } \uparrow \rightarrow \mathrm{CHOP} \uparrow \rightarrow \\
\text { TRB3 } \uparrow \rightarrow \text { AKT } \downarrow\end{array}$ & {$[40,41]$} \\
\hline $\begin{array}{l}\mathrm{IL}-6 \uparrow \rightarrow \mathrm{JAK} \uparrow \rightarrow \mathrm{STAT} 3 \uparrow \rightarrow \mathrm{SOCS} 3 \uparrow \rightarrow \\
\mathrm{IRS} \downarrow\end{array}$ & {$[66-68]$} \\
\hline
\end{tabular}


model, gene expression is represented by either TRUE (1) or FALSE (0). By simplifying the gene expression levels into binary states, Boolean networks are feasible for simulating the behaviour of large regulatory networks in a qualitative way.

In a Boolean network model the state of each gene is represented by either 1 (TRUE), indicating the gene is highly expressed, or 0 (FALSE) when the gene is lowly expressed. An edge in a Boolean network can be either activating or inhibiting [22]. In this paper, we have used random asynchronous Boolean simulation [23, 24], which updates genes in a random order in each iteration. This random asynchronous update method is inspired by the stochastic nature of gene regulatory networks, where gene expression alteration occurs in a random order rather than simultaneously [24].

Due to the lack of experimental gene expression data, we validate our simulation results by comparing predicted patterns of gene expression levels with experimental observations reported in the literature. We also analyze the dynamical behaviors of the model by visualizing the state transition graphs under different combinations of input signals. Our results show that the simple Boolean network model can capture some qualitative trends of the genetic circuits regulating the cell fate decision of $\beta$-cells, and shed light on the causes and processes of dysfunctional insulin metabolism and loss of $\beta$-cell homeostasis that occur in T2DM.

\section{Methods}

In this paper, we propose a Boolean network model of $\beta$-cell fate in T2DM. The model was constructed by extracting information from the KEGG pathways [25] and literature. The gene interactions incorporated into the model with reference to the existing literature are listed in Table 1. In this model, we integrated the $\beta$-cell apoptosis pathway with the insulin resistance pathway, as shown in Fig. 1. The apoptosis pathway consists of the signaling pathways triggered by ER stress (UPR pathway), oxidative stress, and 3 cytokines, i.e. FasL, TNF $\alpha$, and IL-6. The insulin resistance pathways consist of phosphatidylinositide 3-kinase (PI3K)-protein kinase B (PKB or AKT) (KEGG ID: hsa04151), mammalian target of rapamycin (mTOR) (KEGG ID: hsa04150), janus kinase (JAK)- signal transducer and activator of transcription (STAT) (KEGG ID: hsa04630), and insulin (KEGG ID: hsa04910) signaling pathways. T2DM first causes insulin resistance, i.e. insulin fails to bind to insulin receptors in cells, thereby blocking the uptake of blood glucose by cells. Sustained insulin resistance finally leads to $\beta$-cell failure and apoptosis.

The Boolean update functions, listed in Table 2, for the target genes in the model are defined by combining activating input genes using OR functions and inhibiting input genes using AND functions. The reason behind this combination strategy is that a target gene will be expressed when at least one of its activating genes is expressed and all of its inhibiting genes are absent.

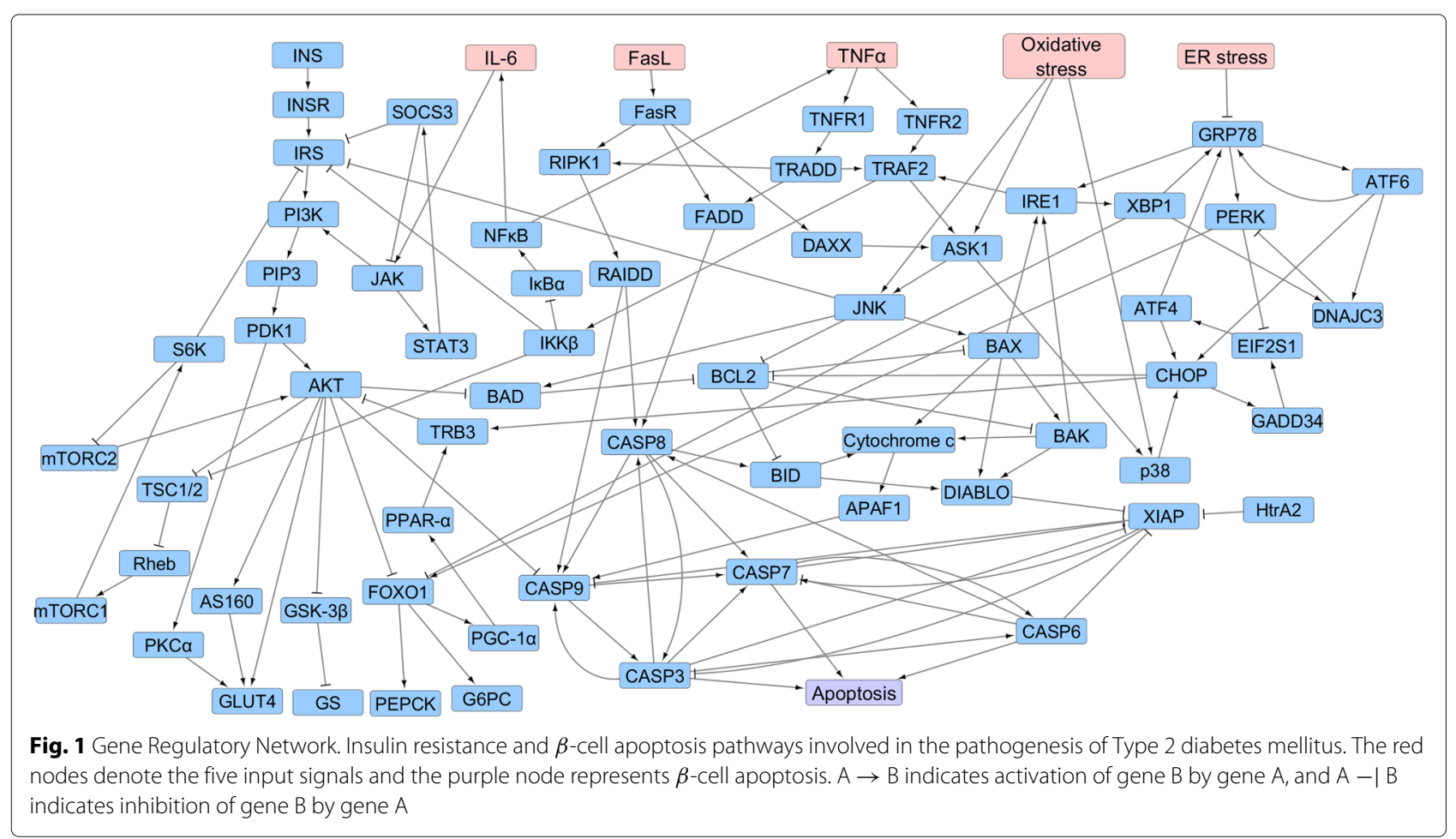


Table 2 Boolean functions for the Boolean model

\begin{tabular}{|c|c|c|c|}
\hline Node & Boolean function & Node & Boolean function \\
\hline ER & ER & OS & OS \\
\hline FasL & FasL & TNF $\alpha$ & TNF $\alpha$ or NFKB \\
\hline IL-6 & IL-6 or NFKB & & \\
\hline GRP78 & $\begin{array}{l}\text { ATF6 or XBP1 or ATF4 } \\
\text { and (not ER) }\end{array}$ & ATF6 & GRP78 \\
\hline PERK & $\begin{array}{l}\text { GRP78 and (not } \\
\text { DNAJC3) }\end{array}$ & IRE1 & BAX or BAK or GRP78 \\
\hline EIF2S1 & $\begin{array}{l}\text { GADD34 and (not } \\
\text { PERK) }\end{array}$ & DNAJC3 & ATF6 or XBP1 \\
\hline ATF4 & EIF2S1 & $\mathrm{CHOP}$ & ATF6 or ATF4 \\
\hline XBP1 & IRE1 & GADD34 & $\mathrm{CHOP}$ \\
\hline TNFR1 & $\mathrm{TNF} \alpha$ & TNFR2 & $\mathrm{TNF} \alpha$ \\
\hline TRAF2 & $\begin{array}{l}\text { IRE1 or TNFR2 or } \\
\text { TRADD }\end{array}$ & ASK1 & OS or TRAF2 or DAXX \\
\hline JNK & $\begin{array}{l}\text { OS or ASK1 or } \\
\text { GADD45 }\end{array}$ & p38 & OS or ASK1 \\
\hline $\mathrm{BCL} 2$ & $\begin{array}{l}\text { (not JNK) and (not } \\
\text { CHOP) and (not P53) } \\
\text { and (not BAD) }\end{array}$ & BID & CASP8 and (not BCL2) \\
\hline BAX & $\begin{array}{l}\text { JNK or P53 and (not } \\
\text { BCL2) }\end{array}$ & BAK & BAX and (not BCL2) \\
\hline DIABLO & $\mathrm{BAX}$ or BAK or BID & $\mathrm{HtrA} 2$ & BAX or BAK or BID \\
\hline FasR & FasL & TRADD & TNFR1 \\
\hline DAXX & FasR & RIPK1 & FasR or TRADD \\
\hline RAIDD & RIPK1 & FADD & FasR or TRADD \\
\hline CASP8 & $\begin{array}{l}\text { RAIDD or FADD or } \\
\text { CASP3 or CASP6 }\end{array}$ & CASP9 & $\begin{array}{l}\text { RAIDD or CASP8 or } \\
\text { CASP3 or APAF1 or } \\
\text { CASP12 and (not } \\
\text { XIAP) and (not AKT) }\end{array}$ \\
\hline CASP3 & $\begin{array}{l}\text { CASP9 or CASP8 and } \\
\text { (not XIAP) }\end{array}$ & CASP7 & $\begin{array}{l}\text { CASP9 or CASP8 or } \\
\text { CASP3 or CASP6 and } \\
\text { (not XIAP) }\end{array}$ \\
\hline CASP6 & CASP7 or CASP3 & & \\
\hline XIAP & $\begin{array}{l}\text { (not DIABLO) and (not } \\
\text { HtrA2) (not CASP3) }\end{array}$ & CytochromeC & BAX or BAK or BID \\
\hline APAF1 & CytochromeC or P53 & Apoptosis & $\begin{array}{l}\text { CASP3 or CASP6 or } \\
\text { CASP7 }\end{array}$ \\
\hline INS & INS & INSR & INS \\
\hline IRS & $\begin{array}{l}\text { INSR and (not SOCS3) } \\
\text { and (not JNK) (not } \\
\text { IKK } \beta \text { ) and (not S6K) }\end{array}$ & PI3K & IRS or JAK \\
\hline PIP3 & PI3K & PDK1 & PIP3 \\
\hline AKT & $\begin{array}{l}\text { PDK1 or mTORC2 and } \\
\text { (not TRB3) }\end{array}$ & AS160 & AKT \\
\hline $\mathrm{PKC} \alpha$ & PDK1 & GLUT4 & AKT or AS160 or PKC $\alpha$ \\
\hline GSK3 $\beta$ & not AKT & GS & $\operatorname{not}$ GSK3 $\beta$ \\
\hline FOXO1 & $\begin{array}{l}\text { PERK and (not AKT) } \\
\text { and (not XBP1) }\end{array}$ & $\mathrm{PGC} 1 \alpha$ & FOXO1 \\
\hline PEPCK & FOXO1 & G6PC & FOXO1 \\
\hline $\operatorname{PPAR} \alpha$ & $\mathrm{PGC} 1 \alpha$ & TRB3 & PPAR $\alpha$ or $\mathrm{CHOP}$ \\
\hline $\mathrm{TSC} 1 / 2$ & $\begin{array}{l}\text { (not AKT) and (not } \\
\text { IKK } \beta \text { ) }\end{array}$ & Rheb & not TSC1/2 \\
\hline mTORC1 & Rheb & S6K & mTORC1 \\
\hline mTORC2 & not S6K & $B A D$ & JNK and (not AKT) \\
\hline JAK & IL-6 and (not SOCS3) & STAT3 & JAK \\
\hline SOCS3 & STAT3 & $\mathbb{I K K} \beta$ & TRAF2 \\
\hline $\mathrm{NF} \kappa \mathrm{B}$ & not IKB $\alpha$ & $\mathrm{IKB} \alpha$ & not IKK $\beta$ \\
\hline
\end{tabular}

The proposed Boolean network consists of 72 nodes, of which five are input signals, one node represents Apoptosis, and the remaining 66 nodes represent genes. We employ the random asynchronous Boolean update [23, 24] method to perform the simulations. The random asynchronous Boolean method first generates a random permutation of the nodes at each time step and updates the states of the nodes in the order specified by the permutation. This allows us to capture the stochastic changes in gene expressions that occur in real gene regulatory networks. The random asynchronous Boolean simulations were performed using the Python code provided in [23] which is available at https:/gitlab.com/ stemcellbioengineering/garuda-boolean.

For example, suppose a gene regulatory network consists of 3 genes, $\left\{g_{1}, g_{2}, g_{3}\right\}$. The Boolean update functions for the genes are as follows:

$$
\begin{aligned}
& g_{1}=g_{3} \\
& g_{2}=g_{1} \vee g_{3} \\
& g_{3}=g_{2}
\end{aligned}
$$

Suppose an iteration randomly generates a permutation of nodes as $\{3,1,2\}$. Then the asynchronous Boolean updates will be carried out as follows:

$$
\begin{aligned}
& g_{3}(t+1)=g_{2}(t) \\
& g_{1}(t+1)=g_{3}(t+1) \\
& g_{2}(t+1)=g_{1}(t+1) \vee g_{3}(t+1)
\end{aligned}
$$

From the above equations, we see that the nodes are updated in a randomly generated order as specified by the permutation, rather than simultaneously.

After performing the simulations for a fixed number of iterations, a directed graph of states is obtained, where each state is a vector representing the expression levels of all genes at a particular time step. The strategy of strongly connected components (SCCs) is employed on this directed graph to capture the dynamic nature of the states [23]. An SCC of a directed graph is a sub-graph that is strongly connected, i.e., each node is reachable from every other node in the sub-graph. An illustration of SCC is given in Fig. 2. Each node is a state with the expression levels of all the genes in the network (for the example we assume a network with five genes) and there is a path between each pair of nodes in both directions. Let us consider that an SCC consists of a set of $N$ states $\left\{S_{1}, S_{2}, \ldots, S_{N}\right\}$. The probability of state $S_{i}$ being one of the states of the SCC is given by:

$$
P\left(S_{i}\right)=\frac{\text { number of occurrences of } S_{i}}{\sum_{j=1}^{N} \text { number of occurrences of } S_{j}} .
$$

We calculate the gene expression level of each gene in a particular SCC as the sum of probabilities of states where the gene is in the ON state. Therefore, the expression level 


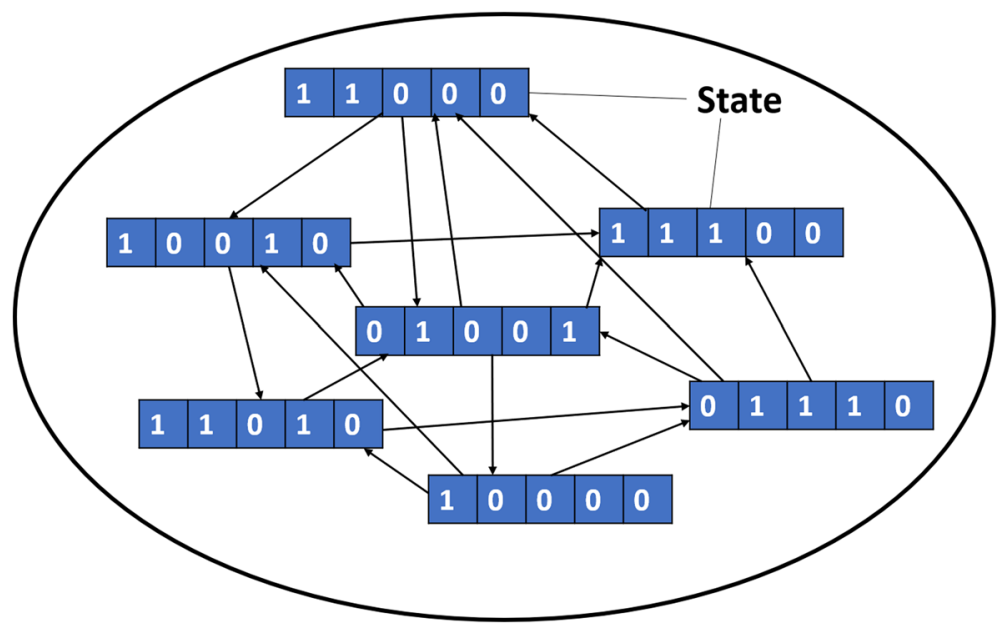

Fig. 2 Strongly Connected Component. An example of a strongly connected component (SCC). Suppose the network consists of five genes. Then each node is a state which contains the expression levels of the five genes. An arrow from state $S_{1}$ to state $S_{2}$ indicates an update step. In an SCC all states can be reached from every other state

of a gene, $g_{i}$, with respect to an SCC is determined as follows:

$$
\operatorname{Exp}\left(g_{i}\right)=\sum_{S_{j} \in \operatorname{OnSt}\left(g_{i}\right)} P\left(S_{j}\right)
$$

where

$$
\operatorname{OnSt}\left(g_{i}\right)=\left\{S_{j} \in S C C \mid g_{i}\left(S_{j}\right)=1\right\} .
$$

It is easy to see that

$$
\sum_{j=1}^{N} P\left(S_{j}\right)=1
$$

We use ER stress, oxidative stress, TNF $\alpha$, FasL, and IL6 as input signals. Also, based on the literature, some of the nodes are assigned specific values (Table 3 ) and the rest are set to random values as initial conditions. We performed simulations using different combinations of the input signals, as shown in Table 4. We carried out 1000 simulation runs and 1000 Boolean update steps per simulation for each input signal. The results of the simulations are presented and discussed in the following section.

Table 3 Initial conditions

\begin{tabular}{lll}
\hline Node & Initial value & Reason \\
\hline Apoptosis & False & $\begin{array}{l}\text { We set apoptosis to False to see } \\
\text { whether the input signals can } \\
\text { cause apoptosis }\end{array}$ \\
Caspases $3,6,7,8,9 \quad$ False & $\begin{array}{l}\text { Caspases serve as the final } \\
\text { mediators of apoptosis. So, we set } \\
\text { them to False to see whether the } \\
\text { input signals can activate them }\end{array}$ \\
& &
\end{tabular}

Due to the lack of experimental data, we validate our proposed Boolean network model using relevant literature (see Table 1). For each gene $g_{i}$, we use the same symbol $g_{i}$ to represent its binary expression level.

$g_{i}= \begin{cases}1 & \text { if } g_{i} \text { is reported as expressed in the literature } \\ 0 & \text { if } g_{i} \text { is reported as not expressed in the literature }\end{cases}$

In our model, we determine the expression level of each gene with respect to a particular SCC. Thus the gene expression levels are in the range $[0,1]$. We assume that if the expression value of a gene is greater than 0.50 , then the gene is expressed, otherwise, it is not expressed.

For the purpose of validating our proposed model, we employ the performance metrics of precision, recall (sensitivity), specificity, and F1 score. The simulation result of our proposed model is verified against the literature as

Table 4 Different combinations for the input signal nodes

\begin{tabular}{llllll}
\hline & ER stress & Oxidative stress & TNF $\alpha$ & FasL & IL-6 \\
\hline Case 1 & True & False & False & False & False \\
Case 2 & False & True & False & False & False \\
Case 3 & True & True & False & False & False \\
Case 4 & False & False & True & False & False \\
Case 5 & False & False & False & True & False \\
Case 6 & False & False & False & False & True \\
Case 7 & False & False & True & True & True \\
Case 8 & True & True & True & True & True \\
\hline
\end{tabular}


Table 5 Gene expressions of the significant genes in the model for input signal cases 1-5 and 7-8

\begin{tabular}{|c|c|c|c|c|c|c|c|c|c|c|c|c|c|c|}
\hline \multirow[t]{2}{*}{ Node } & \multicolumn{2}{|c|}{ Case 1} & \multicolumn{2}{|c|}{ Case 2} & \multicolumn{2}{|c|}{ Case 3} & \multicolumn{2}{|c|}{ Case 4} & \multicolumn{2}{|c|}{ Case 5} & \multicolumn{2}{|c|}{ Case 7} & \multicolumn{2}{|c|}{ Case 8} \\
\hline & A1 & $A 2$ & A1 & $A 2$ & $A 1$ & $A 2$ & A1 & $A 2$ & $A 1$ & $A 2$ & A1 & $A 2$ & A1 & $A 2$ \\
\hline Apoptosis & 1 & 1 & 1 & 1 & 1 & 1 & 1 & 1 & 1 & 1 & 1 & 1 & 1 & 1 \\
\hline AKT & 0.50 & 0.50 & 0.49 & 0.49 & 0.49 & 0.49 & 0.49 & 0.49 & 0.50 & 0.49 & 0.49 & 0.50 & 0.50 & 0.49 \\
\hline APAF-1 & 1 & 1 & 1 & 1 & 1 & 1 & 1 & 1 & 1 & 1 & 1 & 1 & 1 & 1 \\
\hline ASK1 & 1 & 1 & 1 & 1 & 1 & 1 & 1 & 1 & 1 & 1 & 1 & 1 & 1 & 1 \\
\hline ATF4 & 1 & 0 & 1 & 0 & 1 & 0 & 1 & 0 & 1 & 0 & 1 & 0 & 1 & 0 \\
\hline ATF6 & 0 & 0 & 0 & 0 & 0 & 0 & 0 & 0 & 0 & 0 & 0 & 0 & 0 & 0 \\
\hline BAK & 1 & 1 & 1 & 1 & 1 & 1 & 1 & 1 & 1 & 1 & 1 & 1 & 1 & 1 \\
\hline BAX & 1 & 1 & 1 & 1 & 1 & 1 & 1 & 1 & 1 & 1 & 1 & 1 & 1 & 1 \\
\hline BCL2 & 0 & 0 & 0 & 0 & 0 & 0 & 0 & 0 & 0 & 0 & 0 & 0 & 0 & 0 \\
\hline Caspase-3 & 1 & 1 & 1 & 1 & 1 & 1 & 1 & 1 & 1 & 1 & 1 & 1 & 1 & 1 \\
\hline Caspase-6 & 1 & 1 & 1 & 1 & 1 & 1 & 1 & 1 & 1 & 1 & 1 & 1 & 1 & 1 \\
\hline Caspase-7 & 1 & 1 & 1 & 1 & 1 & 1 & 1 & 1 & 1 & 1 & 1 & 1 & 1 & 1 \\
\hline Caspase-8 & 1 & 1 & 1 & 1 & 1 & 1 & 1 & 1 & 1 & 1 & 1 & 1 & 1 & 1 \\
\hline Caspase-9 & 1 & 1 & 1 & 1 & 1 & 1 & 1 & 1 & 1 & 1 & 1 & 1 & 1 & 1 \\
\hline $\mathrm{CHOP}$ & 1 & 0 & 1 & 0 & 1 & 0 & 1 & 0 & 1 & 0 & 1 & 0 & 1 & 0 \\
\hline DIABLO & 1 & 1 & 1 & 1 & 1 & 1 & 1 & 1 & 1 & 1 & 1 & 1 & 1 & 1 \\
\hline EIF2S1 & 1 & 0 & 1 & 0 & 1 & 0 & 1 & 0 & 1 & 0 & 1 & 0 & 1 & 0 \\
\hline FADD & 1 & 1 & 1 & 1 & 1 & 1 & 1 & 1 & 1 & 1 & 1 & 1 & 1 & 1 \\
\hline FASR & 0 & 0 & 0 & 0 & 0 & 0 & 0 & 0 & 0 & 0 & 0 & 0 & 0 & 0 \\
\hline FOXO1 & 0 & 0 & 0 & 0 & 0 & 0 & 0 & 0 & 0 & 0 & 0 & 0 & 0 & 0 \\
\hline G6PC & 0 & 0 & 0 & 0 & 0 & 0 & 0 & 0 & 0 & 0 & 0 & 0 & 0 & 0 \\
\hline GADD34 & 1 & 0 & 1 & 0 & 1 & 0 & 1 & 0 & 1 & 0 & 1 & 0 & 1 & 0 \\
\hline GLUT4 & 0.65 & 0.65 & 0.65 & 0.65 & 0.65 & 0.65 & 0.65 & 0.65 & 0.65 & 0.65 & 0.65 & 0.65 & 0.65 & 0.65 \\
\hline GRP78 & 1 & 1 & 1 & 1 & 1 & 1 & 1 & 1 & 1 & 1 & 1 & 1 & 1 & 1 \\
\hline GS & 0.50 & 0.50 & 0.50 & 0.49 & 0.49 & 0.49 & 0.49 & 0.49 & 0.50 & 0.50 & 0.50 & 0.50 & 0.50 & 0.49 \\
\hline GSK3 $\beta$ & 0.49 & 0.49 & 0.50 & 0.50 & 0.50 & 0.50 & 0.50 & 0.50 & 0.49 & 0.49 & 0.49 & 0.49 & 0.49 & 0.50 \\
\hline $\mathrm{HtrA2}$ & 1 & 1 & 1 & 1 & 1 & 1 & 1 & 1 & 1 & 1 & 1 & 1 & 1 & 1 \\
\hline $\mathrm{IKB} \alpha$ & 0 & 0 & 0 & 0 & 0 & 0 & 0 & 0 & 0 & 0 & 0 & 0 & 0 & 0 \\
\hline $\mathrm{IKK} \beta$ & 1 & 1 & 1 & 1 & 1 & 1 & 1 & 1 & 1 & 1 & 1 & 1 & 1 & 1 \\
\hline INS & 1 & 1 & 1 & 1 & 1 & 1 & 1 & 1 & 1 & 1 & 1 & 1 & 1 & 1 \\
\hline INSR & 1 & 1 & 1 & 1 & 1 & 1 & 1 & 1 & 1 & 1 & 1 & 1 & 1 & 1 \\
\hline IRE1 & 1 & 1 & 1 & 1 & 1 & 1 & 1 & 1 & 1 & 1 & 1 & 1 & 1 & 1 \\
\hline IRS & 0 & 0 & 0 & 0 & 0 & 0 & 0 & 0 & 0 & 0 & 0 & 0 & 0 & 0 \\
\hline JAK & 0.50 & 0.49 & 0.50 & 0.49 & 0.49 & 0.50 & 0.49 & 0.49 & 0.49 & 0.49 & 0.49 & 0.50 & 0.50 & 0.50 \\
\hline JNK & 1 & 1 & 1 & 1 & 1 & 1 & 1 & 1 & 1 & 1 & 1 & 1 & 1 & 1 \\
\hline NFKB & 1 & 1 & 1 & 1 & 1 & 1 & 1 & 1 & 1 & 1 & 1 & 1 & 1 & 1 \\
\hline PEPCK & 0 & 0 & 0 & 0 & 0 & 0 & 0 & 0 & 0 & 0 & 0 & 0 & 0 & 0 \\
\hline PERK & 0 & 0 & 0 & 0 & 0 & 0 & 0 & 0 & 0 & 0 & 0 & 0 & 0 & 0 \\
\hline PI3K & 0.50 & 0.49 & 0.49 & 0.49 & 0.50 & 0.50 & 0.50 & 0.50 & 0.50 & 0.49 & 0.49 & 0.50 & 0.50 & 0.49 \\
\hline RAIDD & 1 & 1 & 1 & 1 & 1 & 1 & 1 & 1 & 1 & 1 & 1 & 1 & 1 & 1 \\
\hline RIPK1 & 1 & 1 & 1 & 1 & 1 & 1 & 1 & 1 & 1 & 1 & 1 & 1 & 1 & 1 \\
\hline S6K & 1 & 1 & 1 & 1 & 1 & 1 & 1 & 1 & 1 & 1 & 1 & 1 & 1 & 1 \\
\hline sOCS3 & 0.49 & 0.49 & 0.50 & 0.49 & 0.50 & 0.50 & 0.49 & 0.49 & 0.50 & 0.50 & 0.49 & 0.49 & 0.49 & 0.50 \\
\hline STAT3 & 0.50 & 0.49 & 0.49 & 0.49 & 0.49 & 0.50 & 0.49 & 0.49 & 0.50 & 0.50 & 0.49 & 0.49 & 0.50 & 0.50 \\
\hline TNFR1 & 1 & 1 & 1 & 1 & 1 & 1 & 1 & 1 & 1 & 1 & 1 & 1 & 1 & 1 \\
\hline TNFR2 & 1 & 1 & 1 & 1 & 1 & 1 & 1 & 1 & 1 & 1 & 1 & 1 & 1 & 1 \\
\hline
\end{tabular}


Table 5 Gene expressions of the significant genes in the model for input signal cases 1-5 and 7-8 (Continued)

\begin{tabular}{|c|c|c|c|c|c|c|c|c|c|c|c|c|c|c|}
\hline \multirow[t]{2}{*}{ Node } & \multicolumn{2}{|c|}{ Case 1} & \multicolumn{2}{|c|}{ Case 2} & \multicolumn{2}{|c|}{ Case 3} & \multicolumn{2}{|c|}{ Case 4} & \multicolumn{2}{|c|}{ Case 5} & \multicolumn{2}{|c|}{ Case 7} & \multicolumn{2}{|c|}{ Case 8} \\
\hline & $\mathrm{A} 1$ & $\mathrm{~A} 2$ & $\mathrm{~A} 1$ & $\mathrm{~A} 2$ & A1 & $A 2$ & $\mathrm{~A} 1$ & $A 2$ & A1 & $A 2$ & $\mathrm{~A} 1$ & $A 2$ & $\mathrm{~A} 1$ & $A 2$ \\
\hline TRADD & 1 & 1 & 1 & 1 & 1 & 1 & 1 & 1 & 1 & 1 & 1 & 1 & 1 & 1 \\
\hline TRAF2 & 1 & 1 & 1 & 1 & 1 & 1 & 1 & 1 & 1 & 1 & 1 & 1 & 1 & 1 \\
\hline TRB3 & 1 & 0 & 1 & 0 & 1 & 0 & 1 & 0 & 1 & 0 & 1 & 0 & 1 & 0 \\
\hline TSC2 & 0 & 0 & 0 & 0 & 0 & 0 & 0 & 0 & 0 & 0 & 0 & 0 & 0 & 0 \\
\hline XBP1 & 1 & 1 & 1 & 1 & 1 & 1 & 1 & 1 & 1 & 1 & 1 & 1 & 1 & 1 \\
\hline XIAP & 0 & 0 & 0 & 0 & 0 & 0 & 0 & 0 & 0 & 0 & 0 & 0 & 0 & 0 \\
\hline mTORC1 & 1 & 1 & 1 & 1 & 1 & 1 & 1 & 1 & 1 & 1 & 1 & 1 & 1 & 1 \\
\hline p38 & 1 & 1 & 1 & 1 & 1 & 1 & 1 & 1 & 1 & 1 & 1 & 1 & 1 & 1 \\
\hline
\end{tabular}

Here $\mathrm{A} 1$ and $\mathrm{A} 2$ denotes SCC1 and SCC2

follows. For each gene $g_{i}$,

$g_{i} \in \begin{cases}\text { True positive, } & \text { if } g_{i}=1 \text { (simulation result) and } g_{i}=1 \text { (literature) } \\ \text { True negative, } & \text { if } g_{i}=0 \text { (simulation result) and } g_{i}=0 \text { (literature) } \\ \text { False positive, } & \text { if } g_{i}=1 \text { (simulation result) and } g_{i}=0 \text { (literature) } \\ \text { False negative, } & \text { if } g_{i}=0 \text { (simulation result) and } g_{i}=1 \text { (literature) }\end{cases}$

The four evaluation metrics are calculated using the following formulae:

$$
\begin{aligned}
& \text { Precision }=\frac{\text { True positive }}{\text { True positive }+ \text { False positive }} \\
& \text { Recallorsensitivity }=\frac{\text { True positive }}{\text { True positive }+ \text { False negative }} \\
& \text { Specificity }=\frac{\text { True negative }}{\text { True negative }+ \text { False positive }} \\
& F 1 \text { score }=\frac{2 \times \text { precision } \times \text { recall }}{\text { precision }+ \text { recall }}
\end{aligned}
$$

\section{Results}

\section{Comparison with the literature}

The expression levels of genes in the SCCs obtained by performing simulations with our proposed Boolean model are listed in Tables 5 and 6 . Simulations performed using input signal cases $1,2,3,4,5,7$, and 8 (Table 4) result in two attractors (SCCs). Apoptosis is $\mathrm{ON}$ in both of the attractors. Simulations performed using input signal case 6 (Table 4) result in six attractors (SCCs). Apoptosis is ON in four attractors and OFF in the remaining two attractors. These observations are consistent with the literature where ER stress, oxidative stress, and cytokines have been shown to cause apoptosis of $\beta$-cells individually as well as together [4-6].

From our simulation results, we observe that Caspases $3,6,7,8$, and 9, which serve as the final mediators of apoptosis [18] are TRUE in the attractors, even though in the initial condition they were set to FALSE. The
ER stress sensor IRE1 and its downstream gene X-box protein binding 1 (XBP1) are TRUE in some attractors, and FALSE in others [26]. Another ER stress sensor, PERK is observed to be FALSE in all the attractors. Also, eukaryotic translation initiation factor 2 subunit 1 (EIF2S1), activating transcription factor 4 (ATF4), and $\mathrm{C} / \mathrm{EBP}$ homologous protein (CHOP) are TRUE in some attractors and FALSE in the others. PERK phosphorylates and inactivates EIF2S1, which inhibits protein synthesis. Phosphorylated EIF2S1 increases the translation of ATF4 [8], which in turn activates pro-apoptotic CHOP, causing $\beta$-cell dysfunction and death [27]. The attractors where IRE1, XBP1, EIF2S1, ATF4, and CHOP have expression levels of 0 may denote the transition states when these genes are not contributing to apoptosis.

While associating with TNF-receptor-associated factor 2 (TRAF2) and apoptosis signal-regulating kinase 1 (ASK1), IRE1 activates jun N-terminal kinase (JNK) [28, 29], which in turn inhibits the anti-apoptotic protein Bcell lymphoma 2 (BCL2) [30]. Oxidative stress activates ASK1 [31, 32], JNK and p38 [33]. Activated p38 phosphorylates and elevates the expression of pro-apoptotic CHOP [34]. From the simulation results, we observe that the pro-apoptotic genes, TRAF2, ASK1, JNK, p38, BAX, and BAK are TRUE and the anti-apoptotic gene BCL2 is FALSE in one attractor, while the reverse states are observed in the other. X-linked inhibitor of apoptosis protein (XIAP), which inhibits Caspases 3, 7, and 9 [35, 36], has an expression level of 0 , whereas direct IAP-binding protein with low pI (DIABLO) and high temperature requirement protein A2 (HtrA2), which inhibit XIAP [37], have expression levels of 1 .

JNK phosphorylates and inhibits insulin receptor substrate (IRS) [38, 39]. IRS gene is FALSE in both of the attractors. PI3K has an expression level of around 0.50 in all the attractors. Tribbles homolog 3 (TRB3) is induced by 
Table 6 Gene expressions of the significant genes in the model for input signal case 6. Here A1-A6 denotes SCC1-SCC6

\begin{tabular}{|c|c|c|c|c|c|c|}
\hline \multirow[t]{2}{*}{ Node } & \multicolumn{6}{|c|}{ Case 6} \\
\hline & $\mathrm{A} 1$ & $\mathrm{~A} 2$ & $\mathrm{~A} 3$ & A4 & A5 & A6 \\
\hline Apoptosis & 1 & 1 & 1 & 1 & 0 & 0 \\
\hline AKT & 0.49 & 0.49 & 0.63 & 0.55 & 0.65 & 0.56 \\
\hline APAF-1 & 1 & 1 & 0 & 1 & 0 & 0 \\
\hline ASK1 & 1 & 1 & 0 & 0 & 0 & 0 \\
\hline ATF4 & 1 & 0 & 0 & 1 & 0 & 1 \\
\hline ATF6 & 0 & 0 & 0 & 0 & 0 & 0 \\
\hline BAK & 1 & 1 & 0 & 0 & 0 & 0 \\
\hline BAX & 1 & 1 & 0 & 0 & 0 & 0 \\
\hline BCL2 & 0 & 0 & 1 & 0 & 1 & 0 \\
\hline Caspase-3 & 1 & 1 & 1 & 1 & 0 & 0 \\
\hline Caspase-6 & 1 & 1 & 1 & 1 & 0 & 0 \\
\hline Caspase-7 & 1 & 1 & 1 & 1 & 0 & 0 \\
\hline Caspase-8 & 1 & 1 & 1 & 1 & 0 & 0 \\
\hline Caspase-9 & 1 & 1 & 1 & 1 & 0 & 0 \\
\hline $\mathrm{CHOP}$ & 1 & 0 & 0 & 1 & 0 & 1 \\
\hline DIABLO & 1 & 1 & 0 & 1 & 0 & 0 \\
\hline EIF2S1 & 1 & 0 & 0 & 1 & 0 & 1 \\
\hline FADD & 1 & 1 & 0 & 0 & 0 & 0 \\
\hline FASR & 0 & 0 & 0 & 0 & 0 & 0 \\
\hline FOXO1 & 0 & 0 & 0 & 0 & 0 & 0 \\
\hline G6PC & 0 & 0 & 0 & 0 & 0 & 0 \\
\hline GADD34 & 1 & 0 & 0 & 1 & 0 & 1 \\
\hline GLUT4 & 0.65 & 0.65 & 0.75 & 0.70 & 0.78 & 0.71 \\
\hline GRP78 & 1 & 1 & 0 & 1 & 0 & 1 \\
\hline GS & 0.49 & 0.49 & 0.62 & 0.54 & 0.65 & 0.55 \\
\hline GSK3 $\beta$ & 0.50 & 0.50 & 0.38 & 0.45 & 0.36 & 0.45 \\
\hline $\mathrm{HtrA2}$ & 1 & 1 & 0 & 1 & 0 & 0 \\
\hline $\mathrm{IKB} \alpha$ & 0 & 0 & 1 & 1 & 1 & 1 \\
\hline $\mathrm{IKK} \beta$ & 1 & 1 & 0 & 0 & 0 & 0 \\
\hline INS & 1 & 1 & 1 & 1 & 1 & 1 \\
\hline INSR & 1 & 1 & 1 & 1 & 1 & 1 \\
\hline IRE1 & 1 & 1 & 0 & 0 & 0 & 0 \\
\hline IRS & 0 & 0 & 0.19 & 0.22 & 0.18 & 0.22 \\
\hline JAK & 0.49 & 0.49 & 0.49 & 0.49 & 0.49 & 0.50 \\
\hline JNK & 1 & 1 & 0 & 0 & 0 & 0 \\
\hline NFKB & 1 & 1 & 0 & 0 & 0 & 0 \\
\hline PEPCK & 0 & 0 & 0 & 0 & 0 & 0 \\
\hline PERK & 0 & 0 & 0 & 0 & 0 & 0 \\
\hline PI3K & 0.49 & 0.49 & 0.54 & 0.55 & 0.54 & 0.56 \\
\hline RAIDD & 1 & 1 & 0 & 0 & 0 & 0 \\
\hline RIPK1 & 1 & 1 & 0 & 0 & 0 & 0 \\
\hline S6K & 1 & 1 & 0.62 & 0.55 & 0.62 & 0.56 \\
\hline SOCS3 & 0.49 & 0.50 & 0.50 & 0.49 & 0.49 & 0.49 \\
\hline STAT3 & 0.49 & 0.49 & 0.49 & 0.49 & 0.49 & 0.50 \\
\hline TNFR1 & 1 & 1 & 0 & 0 & 0 & 0 \\
\hline TNFR2 & 1 & 1 & 0 & 0 & 0 & 0 \\
\hline TRADD & 1 & 1 & 0 & 0 & 0 & 0 \\
\hline
\end{tabular}

Table 6 Gene expressions of the significant genes in the model for input signal case 6. Here A1-A6 denotes SCC1-SCC6 (Continued)

\begin{tabular}{|c|c|c|c|c|c|c|}
\hline \multirow[t]{2}{*}{ Node } & \multicolumn{6}{|c|}{ Case 6} \\
\hline & $\mathrm{A} 1$ & $\mathrm{~A} 2$ & A3 & A4 & A5 & $\overline{A 6}$ \\
\hline TRAF2 & 1 & 1 & 0 & 0 & 0 & 0 \\
\hline TRB3 & 1 & 0 & 0 & 1 & 0 & 1 \\
\hline $\mathrm{TSC} 2$ & 0 & 0 & 0.37 & 0.45 & 0.36 & 0.44 \\
\hline XBP1 & 1 & 1 & 0 & 0 & 0 & 0 \\
\hline XIAP & 0 & 0 & 0 & 0 & 1 & 1 \\
\hline mTORC1 & 1 & 1 & 0.63 & 0.55 & 0.63 & 0.57 \\
\hline p38 & 1 & 1 & 0 & 0 & 0 & 0 \\
\hline
\end{tabular}

ER stress through the ATF4-CHOP pathway [40]. Overexpression of TRB3 inhibits AKT and decreases glucose uptake [41]. TRB3 is TRUE in one attractor and FALSE in the other. AKT has an expression level of 0.50 in both of the attractors. Thus, from the results, we observe that ER stress inhibits the PI3K-AKT signaling pathway and promotes insulin resistance.

Insulin promotes conversion of glucose to glycogen by inhibiting glycogen synthase kinase- $3 \beta$ (GSK $3 \beta)$ through the PI3K-AKT signaling pathway, which leads to the activation of glycogen synthase (GS) [42]. From the simulation results, we observe that the expression level of GSK $3 \beta$, which inhibits glycogen synthesis through inhibition of GS $[42,43]$ is approximately 0.49 and that of GS is approximately 0.50. From these simulation results, we can infer that glycogen synthesis is reduced which contributes to insulin resistance.

In T2DM, the mammalian target of rapamycin complex 1 (mTORC1)/ S6 kinase (S6K) signaling is activated [44] leading to the inhibition of IRS [45, 46]. We observe from the simulation results that mTORC1 and S6K have expression levels of 1 thus inhibiting IRS which has an expression of 0 . These events cause PI3K and AKT to have low expression levels of approximately 0.50 , which in turn reduces glucose uptake through GLUT4 whose expression level is around 0.65 .

FOXO1 increases the expression of phosphoenolpyruvate carboxykinase (PEPCK) and glucose-6-phosphatase (G6PC) and thus promotes glucose synthesis [47]. Insulin inhibits the expression of FOXO1 through the activation of the PI3K/AKT signaling pathway, which in turn suppresses PEPCK and G6PC, and thereby reduces glucose synthesis [47-49]. From our simulation results, we observe that FOXO1, PEPCK, and G6PC are FALSE. This could be due to the fact that PI3K and AKT are not completely inactive, though they may have low expression levels, and hence is still able to inhibit the expressions of FOXO1, PEPCK, and G6PC.

In Case 6 where only signal IL6 is active, we observe six attractors (Table 6), of which four indicate apoptosis 
and two do not. For the attractors where apoptosis is observed, the expression levels of the genes are similar to those mentioned above for the other input signal cases. When apoptosis is not observed, i.e. in the two remaining attractors, the caspases, JNK, BAX, and BAK are FALSE. In one of these two attractors, BCL2 is FALSE and CHOP is TRUE. In the other attractor we observe the reverse expression pattern. Thus, in the presence of only IL- 6 , apoptosis may or may not be activated.

We further assessed the performance of our proposed Boolean network model by comparing model predictions of gene expressions against the literature. Considering the simulation results obtained using the 8 input signals listed in Table 4, the average precision, recall (sensitivity), specificity, and F1 score obtained for our model are $0.9524,0.8,0.875$, and 0.8696 , respectively. We observe that the validation scores for our model are not very high, maybe because our model is sensitive to some missing interactions.

\section{State transition graphs}

Figure 3 shows the state transition graph of the state space generated by simulations conducted using input signal combination given in case 8 (Table 4). The two dense red regions represent the two SCCs where apoptosis is $\mathrm{ON}$. The blue nodes represent states where apoptosis is OFF. Thus from the state transition graph, we observe that, in the presence of all input signals, apoptosis is eventually activated, even though in the initial condition it is set to FALSE.
Figure 4 shows the state transition graph of the state space generated by simulations conducted using input signal combination given in case 6 (Table 4). The four dense red regions represent the four SCCs where apoptosis is ON. The two dense blue regions represent the two SCCs where apoptosis is OFF. Thus from the state transition graph, we observe that, in the presence of only IL-6, apoptosis may or may not be activated.

\section{Comparison with random Boolean networks}

We also compared our Boolean network model with random Boolean network models using the 8 input signal combinations given in Table 4. For cases 1, 2, 3, 4, 5, 7, and 8 we found that the number of attractors obtained by simulating the random Boolean networks ranges from 28 to 177, whereas for our Boolean network model the number of attractors is 2 . Similarly, for case 6 , the number of attractors obtained by simulating the random Boolean networks ranges from 25 to 180, whereas for our Boolean network model the number of attractors is 6 . Thus, from the results we observe that the random Boolean networks typically have large numbers of attractors.

\section{Conclusion}

In this paper, we proposed a Boolean network model of the integrated insulin resistance and $\beta$-cell apoptosis pathways. Such a model, which explores the combined mechanism and interplay between insulin resistance and $\beta$-cell apoptosis in the pathogenesis of T2DM, has not been proposed before. We used the model to simulate the

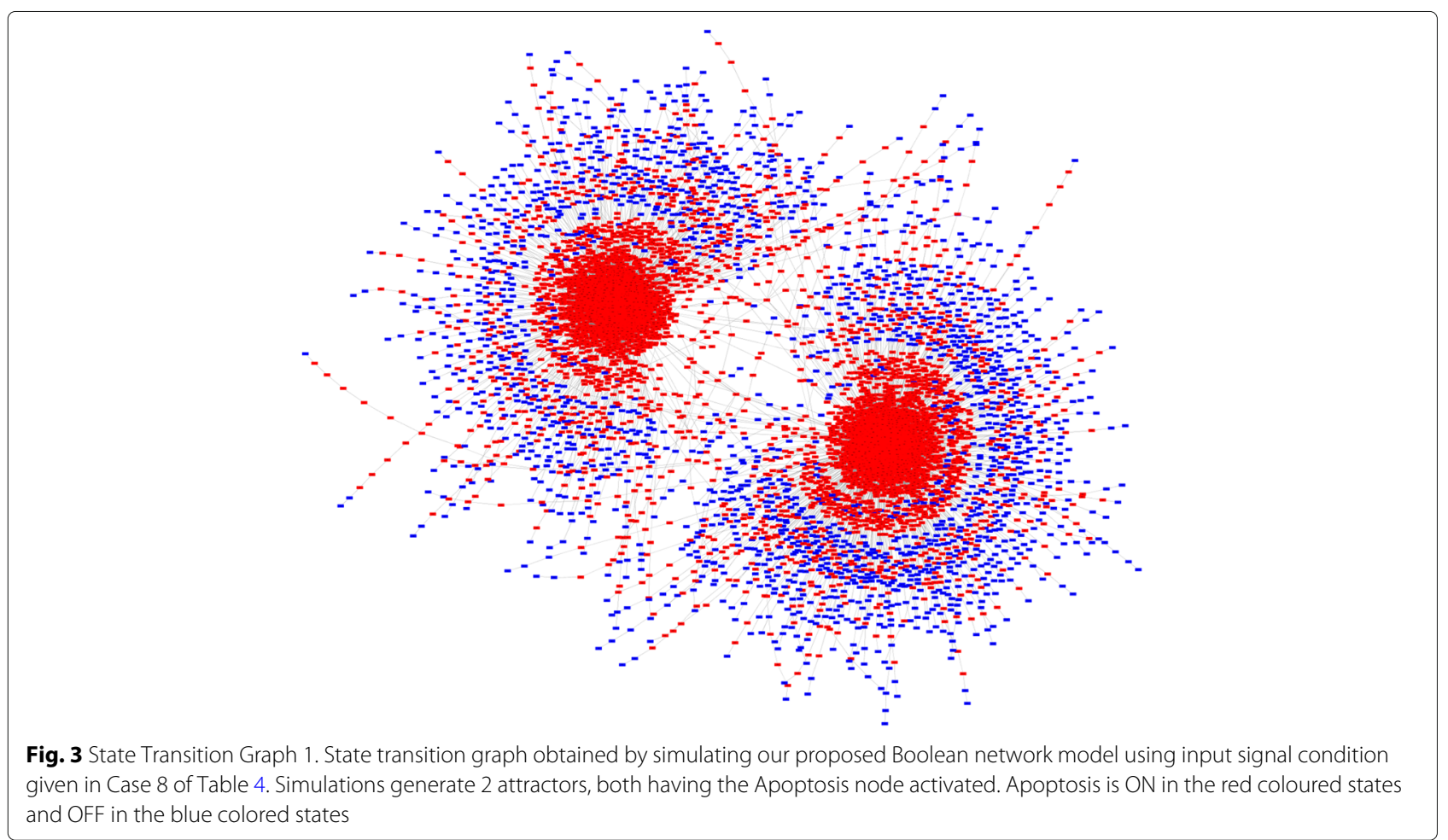




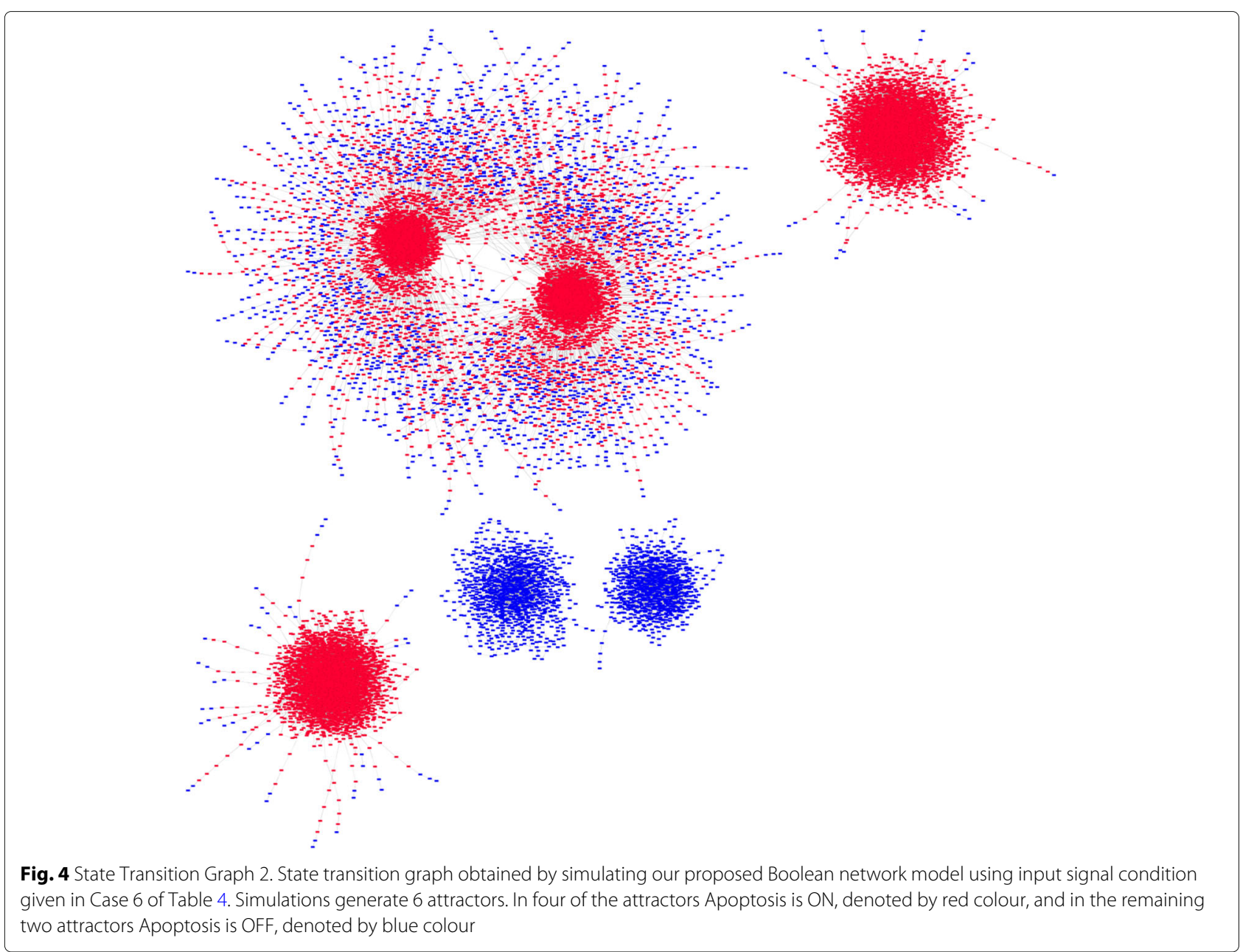

dynamics of gene expression induced by different combinations of the five input signals, i.e. ER stress, oxidativ e stress, and cytokines (TNF $\alpha$, FasL, IL-6), which serve as triggers for insulin resistance and $\beta$-cell apoptosis.

The random order asynchronous update method was employed to perform the simulations, i.e. all nodes were updated in a random order at each update step. We assessed the performance of our model using the metrics of precision, recall (sensitivity), specificity, and F1 score, when validating our model against the literature. The precision score obtained is high, but sensitivity, specificity, and F1 scores are not so. One possible reason may be that some missing interactions affect the predictions of our model. We also compared our Boolean network model with random Boolean network models and observed that random Boolean networks typically have large numbers of attractors ranging from around 25 to 180 , whereas our model shows small numbers of attractors ranging from 2 to 6.

As a future step, we can use this model to perform virtual gene knockout experiments to determine genes that play pivotal roles in insulin resistance and/or $\beta$-cell apoptosis, and these genes could be further investigated for possible disease interventions.

\section{Abbreviations}

AKT (PKB): Protein kinase B; APAF1: Apoptotic protease-activating factor 1 ASK1: Apoptosis signal-regulating kinase 1; ATF4: Activating transcription factor 4; ATF6: Activating Transcription Factor 6; BCL2: B-cell lymphoma 2; CHOP: C/EBP homologous protein; DIABLO: Direct IAP-binding protein with low pl; EIF2S1: Eukaryotic translation initiation factor 2 subunit 1; ER: Endoplasmic reticulum; FADD: Fas-associated death domain-containing protein; FasL: Fas ligand; FasR: Fas receptor; FFA: Free fatty acids; FOXO1: Forkhead box protein 01; GADD34: Growth arrest and DNA damage-inducible protein; G6PC: Glucose-6-phosphatase; GLUT-1: Glucose transporter type 1; GLUT-4: Glucose transporter type 4; GRP78: 78 kDa glucose regulated protein; GS: Glycogen synthase; GSK3 $\beta$ : Glycogen synthase kinase- $3 \beta$; HtrA2: High temperature requirement protein A2; IL-6: Interleukin-6; INSR: Insulin receptor; IRE1: Inositol Requiring 1; IRS: Insulin receptor substrate; JAK: Janus kinase; JNK Jun N-terminal kinase; mTORC1: Mammalian target of rapamycin complex 1; mTORC2: Mammalian target of rapamycin complex 2; ODE: Ordinary differential equation; PEPCK: Phosphoenolpyruvate carboxykinase; PERK: PKR-like ER kinase; PI3K: Phosphatidylinositide 3-kinase; Rheb: Ras homolog enriched in brain; RIPK1: Receptor-interacting serine/threonine-protein kinase 1; ROS: Reactive oxygen species; S6K: S6 kinase; SCC: Strongly connected component; SOCS3: Suppressor of cytokine signaling 3; STAT3: Signal transducer and activator of transcription 3; T2DM: Type 2 Diabetes Mellitus; TNF $\alpha$ : Tumor necrosis factor $\alpha$; TNFR1: Tumor necrosis factor receptor 
superfamily member 1A; TNFR2: Tumor necrosis factor receptor superfamily member 1B; TRADD: TNFR1-associated death domain; TRAF2: TNF-receptor-associated factor 2; TRB3: Tribbles homolog 3; TSC: Tuberous sclerosis complex; UPR: Unfolded pro-tein respons; XBP1: X-box protein binding 1 ; XIAP: $X$-linked inhibitor of apoptosis protein

\section{Acknowledgements}

We would like to thank Dr. Ket Hing Chong for his valuable discussions.

\section{Funding}

This work was supported by MOE AcRF Tier 1 grant (2015-T1-002-094), Ministry of Education, Singapore and the Start-Up Grant of ShanghaiTech University, China. Publication of this article was sponsored by the Start-up Grant of ShanghaiTech University, China.

\section{Availability of data and materials}

Data sharing is not applicable to this article as no datasets were generated or analysed during the current study.

\section{About this supplement}

This article has been published as part of BMC Systems Biology Volume 13 Supplement 2, 2019: Selected articles from the 17th Asia Pacific Bioinformatics Conference (APBC 2019): systems biology. The full contents of the supplement are available online at https://bmcsystbiol.biomedcentral.com/articles/ supplements/volume-13-supplement-2.

\section{Authors' contributions}

IZ initiated the project and idea, PD and LM constructed the model, and PD carried out the simulations and analysis; YA provided biological input, PS gave suggestions on modeling; PD drafted the manuscript with critical input from $J Z$, and other authors provided comments on the manuscript. All authors have read and approved the final manuscript.

\section{Ethics approval and consent to participate}

Not applicable.

\section{Consent for publication}

Not applicable.

\section{Competing interests}

The authors declare that they have no competing interests.

\section{Publisher's Note}

Springer Nature remains neutral with regard to jurisdictional claims in published maps and institutional affiliations.

\section{Author details}

${ }^{1}$ Interdisciplinary Graduate School, Nanyang Technogical University, Singapore, Republic of Singapore. ${ }^{2}$ Biomedical Informatics Lab, School of Computer Science and Engineering, Nanyang Technological University, Singapore, Republic of Singapore. ${ }^{3}$ Lee Kong Chian School of Medicine, Nanyang Technogical University, Singapore, Republic of Singapore.

${ }^{4}$ Complexity Institute, Nanyang Technogical University, Singapore, Republic of Singapore. ${ }^{5}$ School of Information Science and Technology, ShanghaiTech University, Shanghai, China.

\section{Published: 5 April 2019}

\section{References}

1. Tomita T. Apoptosis in pancreatic $\beta$-islet cells in type 2 diabetes. Bosnian J Basic Med Sci. 2016;16(3):162.

2. Butler $A E$, Janson J, Bonner-Weir S, Ritzel R, Rizza RA, Butler PC. $\beta$-cell deficit and increased $\beta$-cell apoptosis in humans with type 2 diabetes. Diabetes. 2003;52(1):102-10.

3. Cnop M, Welsh N, Jonas J-C, Jörns A, Lenzen S, Eizirik DL. Mechanisms of pancreatic $\beta$-cell death in type 1 and type 2 diabetes: many differences, few similarities. Diabetes. 2005;54(suppl 2):97-107.

4. Harding HP, Ron D. Endoplasmic reticulum stress and the development of diabetes: a review. Diabetes. 2002;51 (suppl 3):455-61.

5. Oyadomari S, Araki E, Mori M. Endoplasmic reticulum stress-mediated apoptosis in pancreatic $\beta$-cells. Apoptosis. 2002;7(4):335-45.
6. Schröder M, Kaufman RJ. The mammalian unfolded protein response. Annu Rev Biochem. 2005;74:739-89.

7. Bertolotti A, Zhang Y, Hendershot LM, Harding HP, Ron D. Dynamic interaction of bip and er stress transducers in the unfolded-protein response. Nat Cell Biol. 2000;2(6):326.

8. Ron D, Walter P. Signal integration in the endoplasmic reticulum unfolded protein response. Nat Rev Mol Cell Biol. 2007;8(7):519.

9. Erguler K, Pieri M, Deltas C. A mathematical model of the unfolded protein stress response reveals the decision mechanism for recovery, adaptation and apoptosis. BMC Syst Biol. 2013;7(1):16.

10. Ihara Y, Toyokuni S, Ichida K, Odaka H, et al. Hyperglycemia causes oxidative stress in pancreatic beta-cells of gk rats, a model of type 2 diabetes. Diabetes. 1999;48(4):927.

11. Donath MY, Shoelson SE. Type 2 diabetes as an inflammatory disease. Nat Rev Immunol. 2011;11(2):98.

12. Maedler K, Spinas GA, Lehmann R, Sergeev P, Weber M, Fontana A, Kaiser N, Donath MY. Glucose induces $\beta$-cell apoptosis via upregulation of the fas receptor in human islets. Diabetes. 2001;50(8):1683-90.

13. Spranger J, Kroke A, Möhlig M, Hoffmann K, Bergmann MM, Ristow M, Boeing $\mathrm{H}$, Pfeiffer AF. Inflammatory cytokines and the risk to develop type 2 diabetes: results of the prospective population-based european prospective investigation into cancer and nutrition (epic)-potsdam study. Diabetes. 2003;52(3):812-7.

14. Eizirik DL, Mandrup-Poulsen T. A choice of death-the signal-transduction of immune-mediated beta-cell apoptosis. Diabetologia. 2001;44(12): 2115-33.

15. Donath MY. Targeting inflammation in the treatment of type 2 diabetes: time to start. Nat Rev Drug Discov. 2014;13(6):465-76.

16. Shoelson SE, Lee J, Goldfine AB. Inflammation and insulin resistance. J Clin Investig. 2006;1 16(7):1793-801.

17. Hameed I, Masoodi SR, Mir SA, Nabi M, Ghazanfar K, Ganai BA. Type 2 diabetes mellitus: from a metabolic disorder to an inflammatory condition. World J Diabetes. 2015;6(4):598.

18. Hui H, Dotta F, Mario UD, Perfetti R. Role of caspases in the regulation of apoptotic pancreatic islet beta-cells death. J Cell Physiol. 2004;200(2): 177-200.

19. Brannmark C, Nyman E, Fagerholm S, Bergenholm L, Ekstrand E-M, Cedersund G, Stralfors P. Insulin signaling in type 2 diabetes-experimental and modeling analyses reveal mechanisms of insulin resistance in human adipocytes. J Biol Chem. 2013;288(14):9867-80.

20. Rajan MR, Nyman E, Brännmark C, Olofsson CS, Strålfors P. Inhibition of foxo1 transcription factor in primary human adipocytes mimics the insulin resistant state of type 2 diabetes. Biochem J. 2018;475:1807-20.

21. Sarkar J, Dwivedi G, Chen Q, Sheu IE, Paich M, Chelini CM, D'Alessandro PM, Burns SP. A long-term mechanistic computational model of physiological factors driving the onset of type 2 diabetes in an individual. PLOS ONE. 2018;13(2):0192472.

22. Albert I, Thakar J, Li S, Zhang R, Albert R. Boolean network simulations for life scientists. Source Code Biol Med. 2008;3(1):16.

23. Yachie-Kinoshita A, Onishi K, Ostblom J, Langley MA, Posfai E, Rossant J, Zandstra PW. Modeling signaling-dependent pluripotency with boolean logic to predict cell fate transitions. Mol Syst Biol. 2018;14(1):7952.

24. Albert R, Thakar J. Boolean modeling: a logic-based dynamic approach for understanding signaling and regulatory networks and for making useful predictions. Wiley Interdiscip Rev Syst Biol Med. 2014;6(5):353-69.

25. Kanehisa M, Goto S. Kegg: Kyoto encyclopedia of genes and genomes. Nucleic Acids Res. 2000;28(1):27-30.

26. Allagnat F, Christulia F, Ortis F, Pirot P, Lortz S, Lenzen S, Eizirik DL, Cardozo AK. Sustained production of spliced $x$-box binding protein 1 (xbp1) induces pancreatic beta cell dysfunction and apoptosis. Diabetologia. 2010;53(6):1120-30.

27. Oyadomari S, Mori M. Roles of chop/gadd 153 in endoplasmic reticulum stress. Cell Death Differ. 2004;11(4):381.

28. Urano F, Wang $X$, Bertolotti A, Zhang Y, Chung P, Harding HP, Ron D. Coupling of stress in the er to activation of jnk protein kinases by transmembrane protein kinase ire1. Science. 2000;287(5453):664-6

29. Lipson KL, Fonseca SG, Ishigaki S, Nguyen LX, Foss E, Bortell R, Rossini AA, Urano F. Regulation of insulin biosynthesis in pancreatic beta cells by an endoplasmic reticulum-resident protein kinase ire1. Cell Metab. 2006;4(3): $245-54$. 
30. Xu C, Bailly-Maitre B, Reed JC. Endoplasmic reticulum stress: cell life and death decisions. J Clin Investig. 2005;115(10):2656-64.

31. Ray PD, Huang B-W, Tsuji Y. Reactive oxygen species (ros) homeostasis and redox regulation in cellular signaling. Cell Signal. 2012;24(5):981-90.

32. Tobiume K, Matsuzawa A, Takahashi T, Nishitoh H, Morita K-i, Takeda K, Minowa O, Miyazono K, Noda T, Ichijo H. Ask1 is required for sustained activations of jnk/p38 map kinases and apoptosis. EMBO Rep. 2001;2(3): 222-8.

33. Evans JL, Goldfine ID, Maddux BA, Grodsky GM. Oxidative stress and stress-activated signaling pathways: a unifying hypothesis of type 2 diabetes. Endocr Rev. 2002;23(5):599-622.

34. Wang $X$, Ron D. Stress-induced phosphorylation and activation of the transcription factor chop (gadd153) by p38 map kinase. Science. 1996:272(5266):1347-9.

35. Tenev T, Zachariou A, Wilson R, Ditzel M, Meier P. laps are functionally non-equivalent and regulate effector caspases through distinct mechanisms. Nat Cell Biol. 2005;7(1):70.

36. Holcik M, Gibson H, Korneluk RG. Xiap: apoptotic brake and promising therapeutic target. Apoptosis. 2001;6(4):253-61.

37. Saelens X, Festjens N, Walle LV, Van Gurp M, van Loo G, Vandenabeele P. Toxic proteins released from mitochondria in cell death. Oncogene. 2004;23(16):2861.

38. Aguirre V, Uchida T, Yenush L, Davis R, White MF. The c-jun nh2-terminal kinase promotes insulin resistance during association with insulin receptor substrate-1 and phosphorylation of ser307. J Biol Chem. 2000;275(12):9047-54.

39. Hirosumi J, Tuncman G, Chang L, Görgün CZ, Uysal KT, Maeda K, Karin M, Hotamisligil GS. A central role for jnk in obesity and insulin resistance. Nature. 2002;420(6913):333.

40. Ohoka N, Yoshii S, Hattori T, Onozaki K, Hayashi H. Trb3, a novel er stress-inducible gene, is induced via atf4-chop pathway and is involved in cell death. EMBO J. 2005;24(6):1243-55.

41. Koh H-J, Toyoda T, Didesch MM, Lee M-Y, Sleeman MW, Kulkarni RN, Musi N, Hirshman MF, Goodyear LJ. Tribbles 3 mediates endoplasmic reticulum stress-induced insulin resistance in skeletal muscle. Nat Commun. 2013:4:1871.

42. Cohen P, Frame S. The renaissance of gsk3. Nat Rev Mol Cell Biol. $2001 ; 2(10): 769$.

43. Lee J, Kim M-S. The role of gsk3 in glucose homeostasis and the development of insulin resistance. Diabetes Res Clin Pract. 2007;77(3): 49-57.

44. Khamzina L, Veilleux A, Bergeron S, Marette A. Increased activation of the mammalian target of rapamycin pathway in liver and skeletal muscle of obese rats: possible involvement in obesity-linked insulin resistance. Endocrinology. 2005;146(3):1473-81.

45. Harrington LS, Findlay GM, Gray A, Tolkacheva T, Wigfield S, Rebholz H, Barnett J, Leslie NR, Cheng S, Shepherd PR, et al. The tsc1-2 tumor suppressor controls insulin-pi3k signaling via regulation of irs proteins. J Cell Biol. 2004;166(2):213-23.

46. Shah OJ, Wang Z, Hunter T. Inappropriate activation of the tsc/rheb/mtor/s6k cassette induces irs 1/2 depletion, insulin resistance, and cell survival deficiencies. Curr Biol. 2004;14(18):1650-6.

47. Cheng Z, White MF. Targeting forkhead box o1 from the concept to metabolic diseases: lessons from mouse models. Antioxid Redox Signal. 2011;14(4):649-61.

48. Kousteni S. Foxo1, the transcriptional chief of staff of energy metabolism. Bone. 2012;50(2):437-43.

49. Barthel A, Schmoll D. Novel concepts in insulin regulation of hepatic gluconeogenesis. Am J Physiol Endocrinol Metab. 2003;285(4):685-92.

50. Wei MC, Zong W-X, Cheng EH-Y, Lindsten T, Panoutsakopoulou V, Ross AJ, Roth KA, MacGregor GR, Thompson CB, Korsmeyer SJ. Proapoptotic bax and bak: a requisite gateway to mitochondrial dysfunction and death. Science. 2001;292(5517):727-30.

51. McCullough KD, Martindale JL, Klotz L-O, Aw T-Y, Holbrook NJ. Gadd153 sensitizes cells to endoplasmic reticulum stress by down-regulating bcl 2 and perturbing the cellular redox state. Mol Cell Biol. 2001;21(4):1249-59.

52. Marciniak SJ, Yun CY, Oyadomari S, Novoa I, Zhang $Y$, Jungreis $R$, Nagata K, Harding HP, Ron D. Chop induces death by promoting protein synthesis and oxidation in the stressed endoplasmic reticulum. Gene Dev. 2004;18(24):3066-77.
53. Emamaullee JA, Shapiro AJ. Interventional strategies to prevent $\beta$-cell apoptosis in islet transplantation. Diabetes. 2006;55(7):1907-14.

54. Baud V, Karin M. Signal transduction by tumor necrosis factor and its relatives. Trends Cell Biol. 2001;11(9):372-7.

55. Akash H, Sajid M, Rehman K, Liaqat A. Tumor necrosis factor-alpha: Role in development of insulin resistance and pathogenesis of type 2 diabetes mellitus. J Cell Biochem. 2018;119:105-10.

56. Reinhard C, Shamoon B, Shyamala V, Williams LT. Tumor necrosis factor $\alpha$-induced activation of c-jun n-terminal kinase is mediated by traf2. EMBO J. 1997;16(5):1080-92.

57. Rothe M, Sarma V, Dixit VM, Goeddel DV. Traf2-mediated activation of nf-kappa b by tnf receptor 2 and cd40. Science. 1995;269(5229):1424-7.

58. Li P, Nijhawan D, Budihardjo I, Srinivasula SM, Ahmad M, Alnemri ES, Wang X. Cytochrome $c$ and datp-dependent formation of apaf-1/caspase-9 complex initiates an apoptotic protease cascade. Cell. 1997;91(4):479-89.

59. Perry RJ, Samuel VT, Petersen KF, Shulman Gl. The role of hepatic lipids in hepatic insulin resistance and type 2 diabetes. Nature. 2014;510(7503):84.

60. Nikoulina SE, Ciaraldi TP, Mudaliar S, Mohideen P, Carter L, Henry RR. Potential role of glycogen synthase kinase-3 in skeletal muscle insulin resistance of type 2 diabetes. Diabetes. 2000;49(2):263-71.

61. Favaretto F, Milan G, Collin GB, Marshall JD, Stasi F, Maffei P, Vettor R, Naggert JK. Glut4 defects in adipose tissue are early signs of metabolic alterations in alms1gt/gt, a mouse model for obesity and insulin resistance. PloS ONE. 2014;9(10):109540.

62. Lee D-F, Kuo H-P, Chen C-T, Hsu J-M, Chou C-K, Wei Y, Sun H-L, Li L-Y, Ping $B$, Huang $W-C$, et al. Ikk $\beta$ suppression of tsc 1 links inflammation and tumor angiogenesis via the mtor pathway. Cell. 2007;130(3):440-55.

63. Özcan U, Cao Q, YilmazE, Lee A-H, Iwakoshi NN, Özdelen E, Tuncman G, Görgün C, Glimcher LH, Hotamisligil GS. Endoplasmic reticulum stress links obesity, insulin action, and type 2 diabetes. Science. 2004;306(5695): 457-61.

64. Zhou Y, Lee J, Reno CM, Sun C, Park SW, Chung J, Lee J, Fisher SJ, White MF, Biddinger SB, et al. Regulation of glucose homeostasis through a xbp-1-foxo1 interaction. Nat Med. 2011;17(3):356.

65. Zhang W, Hietakangas V, Wee S, Lim SC, Gunaratne J, Cohen SM. Er stress potentiates insulin resistance through perk-mediated foxo phosphorylation. Genes Dev. 2013;27(4):441-9.

66. Klover PJ, Clementi AH, Mooney RA. Interleukin-6 depletion selectively improves hepatic insulin action in obesity. Endocrinology. 2005;146(8): 3417-27.

67. Klover PJ, Zimmers TA, Koniaris LG, Mooney RA. Chronic exposure to interleukin-6 causes hepatic insulin resistance in mice. Diabetes. 2003;52(11):2784-9.

68. Howard JK, Flier JS. Attenuation of leptin and insulin signaling by socs proteins. Trends Endocrinol Metab. 2006;17(9):365-71.
Ready to submit your research? Choose BMC and benefit from:

- fast, convenient online submission

- thorough peer review by experienced researchers in your field

- rapid publication on acceptance

- support for research data, including large and complex data types

- gold Open Access which fosters wider collaboration and increased citations

- maximum visibility for your research: over 100M website views per year

At BMC, research is always in progress.

Learn more biomedcentral.com/submissions 